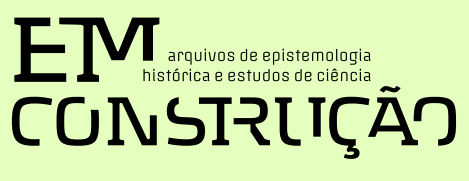

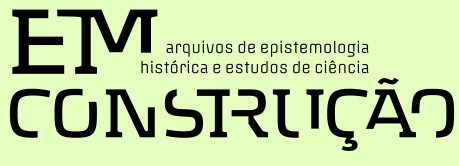

DOI: $10.12957 /$ emconstrucao.2020.54660

www.e-publicacoes.uerj.br/index.php/emconstrucao

\title{
As ciências da vida e o mundo pós-pandemia ${ }^{1}$
}

\author{
Life sciences and the post-pandemic world
}

\author{
Wigson Rafael Silva da Costa - Mestrando PPGFIL UERJ \\ Orcid: https://orcid.org/0000-0002-1926-1716 \\ Prof $^{\text {a }}$. Dra. Vera Portocarrero - Universidade do Estado do Rio de Janeiro \\ Orcid: https://orcid.org/0000-0003-2700-8240
}

Prof. Dr. Vinícius Carvalho da Silva - Universidade Federal do Mato Grosso do Sul viniciusfilo@gmail.com

Orcid: https://orcid.org/0000-0002-1061-2727

Data de recebimento: 22/09/2020

Data de aceite: 22/09/2020

\section{Apresentação}

Atendendo aos apelos dos seguidores e estimulado pelo fatídico cenário pandêmico que se impôs, durante os dias 17 e 19 de junho, o Canal no Youtube intitulado Café com Nietzsche, fundado e administrado pelo mestrando Wigson Rafael Silva da Costa, realizou duas livestreaming que traziam como temática central "As ciências da vida e o mundo pós-pandemia". Para tanto, quatro entrevistados foram convidados a fomentar reflexões e problemáticas que possibilitariam, sobretudo ao grande público, o acesso a uma discussão multidisciplinar e acessível sobre a pandemia da covid-19 e suas implicações científicas, políticas, sociais e econômicas.

Em face da repercussão positiva da segunda livestreaming, protagonizada pelos professores Dr. Vinícius Carvalho da Silva e Dra. Vera Portocarreto, consideramos pertinente transcrever as principais questões suscitadas para o formato de entrevista e, assim, submetê-la a este dossiê. Deste modo, agradecemos a revista Em construção pela oportunidade de publicarmos este trabalho que cremos contribuir com uma linguagem acessível, mas sem ser superficial, para as discussões que emergiram do cenário pandêmico.

Nesta transcrição, foram realizadas algumas modificações gramaticais, bem como alterações no ordenamento das perguntas, a fim de darmos maior fluidez e coerência à fala dos participantes. Ademais, $o$ leitor deve estar atento para o fato de que, na entrevista que se segue, embora recursos inevitáveis de edição

1 Transcrição das principais questões fomentadas na 2a live streaming da série "As ciências da vida e o mundo póspandemia" do canal de Youtube "Café com Nietzsche". 
tenham sido adotados, buscamos respeitar ao máximo a oralidade, observando a espontaneidade dos atos de fala dos participantes durante a livestreaming. Todo conteúdo pode ser ratificado através do Canal do Café com Nietzsche, no Youtube.

RAFAEL (CAFÉ COM NIETZSCHE) - Uma das primeiras questões que nós selecionamos para os entrevistados diz respeito à ontologia das entidades biopatológicas, que pode ser sintetizada na pergunta: “O que é o vírus?”.

VINÍCIUS CARVALHO (UFMS) - Rafael, farei uma digressão para poder chegar ao enfrentamento direto dessa questão. Nós temos uma paixão em comum que é a Filosofia da Física. Vamos tentar situar a discussão da natureza das entidades físicas para depois pensarmos o problema na epistemologia das ciências biomédicas. O que vou chamar de entidades biopatológicas, ou nosológicas, não são necessariamente entidades físicas vivas, mas entidades físicas que impactam sistemas vivos. Por analogia ao problema presente na Filosofia da Física nós poderíamos perguntar: Qual a natureza das entidades inobserváveis? Qual a natureza dos átomos, dos quarks, das bolas de glúons? Serão instrumentos de cálculo, estruturas matemáticas puramente abstratas, ou serão entidades físicas objetivamente reais? Essa discussão pode parecer esotérica demais, mas é extremamente viva no campo da Filosofia da Física, vindo à tona entre os próprios físicos. Por exemplo, e isso tem diretamente a ver com o nosso problema, na passagem do século XIX para o século XX, a natureza do átomo estava em disputa, era uma questão em aberto. Físicos-filósofos como Ernst Mach defendiam que o átomo era um instrumento de cálculo. Albert Einstein, tanto em sua tese de doutorado, quanto em um dos artigos do ano miraculoso, de 1905, desenvolve trabalhos de dimensionamento do tamanho real das moléculas, se posicionando a favor do realismo de entidades. Einstein, discordando de Mach, defenderá que os átomos são entidades físicas objetivas, e não meras imagens, representações, ou instrumentos de cálculo. Se nós pensarmos na história das ciências biomédicas, por analogia, algo parecido ocorre. O que são bactérias? O que são vírus? O que são doenças? O que é a covid-19? A partir de uma perspectiva do realismo ingênuo, nós naturalizamos essas entidades biopatológicas como se fossem dados brutos da natureza, mas se nós nos atentarmos para a complexidade da História das ciências biomédicas veremos que essas entidades, em um determinado momento, estiveram em disputa. Bruno Latour e Steve Woolgar, em A Vida de laboratório, estabelecem um espectro de níveis de facticidade. Eles defendem uma espécie de realismo ascendente em que as entidades biológicas, biofísicas e bioquímicas têm sua realidade construída ao longo do processo histórico. Então, o vírus não nasce pronto. O conceito de vírus é resultado de uma construção histórica complexa, com disputas epistemológicas, políticas e institucionais. Não é um dado bruto da natureza. Quando aquilo que um dia, no laboratório, foi uma hipótese, um modelo explicativo, se torna um fato, esse ente perde a sua história, sendo naturalizado. Passamos a lidar com aquilo como se o mundo sempre tivesse sido daquela forma, como se aquela entidade física sempre tivesse sido um dado bruto da natureza. Ludwik Fleck, antes de Latour, desenvolve um raciocínio análogo, em Gênese e desenvolvimento de um fato científico. Para Fleck, as doenças e as entidades nosológicas seriam construções dos cientistas, construções dos médicos. Mas isso não significa que eles assumam um relativismo extremo. Essas construções conceituais só ganham substancia ontológica quando correspondem a algo no real. Ora, o que é o vírus? O vírus, em sentido ontológico, é uma entidade real cuja história é complexa, e que veio-a-ser considerado aquilo que é a partir de uma história de disputas teóricas, de querelas, de tensões.

VERA PORTOCARRERO (UERJ) - Eu gostaria de comentar esse posicionamento do professor Vinícius colocando, primeiramente, a questão da vida. A questão do aparecimento da vida e do homem no panorama da história das ciências da vida. Vinícius já citou Fleck e Bruno Latour. Este último irá dizer que para fazer uma análise da microbiologia, por exemplo, a microbiologia pastoriana, de Pasteur (e não pasteuriana, para se diferenciar da técnica de pasteurização), devemos levar em conta todas as relações de força que estão em jogo, todos os atores que estão em jogo, nesse caso, inclusive do vírus. Todos os atores que estão em jogo são forças, e são forças humanas e não humanas. No momento, estamos levando uma "surra" das não humanas. E quem são as forças não humanas? Então, vem esse problema que o professor Vinícius estava colocando. 
Até que ponto eu tenho o elemento ainda em um plano metafísico, lógico, científico, que é especulativo, e até que ponto temos aquilo vai aparecer e ser naturalizado, como no caso histórico do vírus-vacina de Pasteur? Faço aqui uma leitura mais histórica, de história da ciência e da filosofia, em que Pasteur foi passando da cristalografia, da óptica para a fermentação do vinho... E ele vai passando por várias etapas de ciências, como diz o Latour, angariando cada vez mais aliados, mais personagens. Até o momento em que, no laboratório, Pasteur diz que a gota d'água no microscópio, na qual Van Leeuwenhoek não viu nada e não entendeu nada cientificamente, Pasteur disse que esses bastõezinhos que estão se mexendo... Isso é a vida! A vida é aquilo que eu não vou poder produzir no laboratório sem já ter um ponto de partida vivo. Esse é um ponto que acho interessante porque o Latour vai trabalhar com ângulos dos deslocamentos. Ele vai traçar um ângulo do deslocamento das forças implicadas, para mostrar como vão se constituindo saberes das ciências da vida, o exemplo de Pasteur é bom por isso, visto que ele começa com a fermentação do vinho até pegar a ideia do Jenner, da Cowpox, da virulência atenuada, achando inclusive que o vírus era vida, e que poderíamos atenuar sua força. Hoje em dia, o que vejo é um debate muito grande sobre até que ponto o vírus não é bem assim vida ou não vida. Mas a realidade que gostaria de levantar é a seguinte: A partir do século XIX, para que nós tenhamos formulado as ciências da vida, e elas foram formuladas a partir de uma "biologização" dos seres concretos, isto é, a Biologia como sendo um esteio não metafísico para se estudar a vida, nós temos uma passagem que tem um momento epistemológico fundamental, e esse momento é abordado por Georges Canguilhem, por François Jacob, por Foucault, que diz respeito ao movimento de afirmação do vitalismo. Por que isso? Porque, com a ideia de uma renovação da noção de vitalismo, seria possível constituir um saber que não se confundiria nem com a Física e nem com a Química. Claro que depois com a biologia molecular tudo isto vai sendo colocado de outro modo... Mas, inicialmente, foi preciso um certo vitalismo, que teve um desdobramento durante o século XIX e durante o século XX até chegar à ideia do vírus e, sobretudo, do vírus-vacina. Este é um conceito importante que encontrei nos textos de Química de Pasteur; porque ele pode, então, mexer com aquilo que ele está vendo no microscópio, aquilo que Van Leeuwenhoek não viu, os bastonetes. Daí a ideia dele, já naquela época de atenuação do vírus, que é muito importante para o Brasil porque o momento de introdução do modelo microbiano na medicina brasileira, sobretudo com Oswaldo Cruz, vem com uma leitura pesada de Pasteur, apesar de depois ele cortar os laços evidentemente e estudar também os alemães. Então, essa discussão, historicamente falando, precisou de uma pitada de vitalismo para poder ser colocada e para hoje discutirmos se vírus tem vida, se vírus não é vida, se precisa de uma vida, etc.

RAFAEL (CAFÉ COM NIETZSCHE) - No quesito da medicalização da sociedade, parece que já temos um histórico problemático neste aspecto, e não apenas em nossos dias, visto que observamos, no início do século $\mathrm{XX}$, este tipo de deficiência.

VERA PORTOCARRERO (UERJ) - Não é propriamente uma deficiência. A medicalização é um modo de funcionar que diz respeito ao papel que a medicina vai exercer até no seu próprio exterior. Que exterior? O que não é propriamente só a doença e o doente. Historicamente, desde a Grécia, a medicina tem um caráter bastante moral, bastante ético, bastante político, mas metafísico também. E, com o tempo, com a passagem para o século XIX, a medicina vai se cientificizar, mas sempre cobrindo um campo social... Como diz Foucault: o doente se oferece ao estado duas vezes, na passagem do século XIX para o século XX. Ele se oferece para o Estado, primeiro, como mão de obra, o seu corpo vai aparecer como mão de obra. E, pela segunda vez, como saúde e doença. Até porque há uma implicação, desde as priscas eras, de a medicina ter uma relação com as instituições de caridade. Então, a medicina era mais voltada para a pobreza, e o Estado cuidava menos da pobreza. Aos poucos é que nós vamos vendo, com o advento de uma economia política, com o capital, isso que faz com que o Estado tenha um papel preponderantemente de gestor da vida dos indivíduos e das populações. Nessa gestão, ele precisa majorar a vida. E para majorar, evidentemente, o Estado vai ter uma série de elementos medicalizadores, normalizadores, científicos, que vão desde a economia, a estatística etc até a justiça, a religiosidade, a cultura. Essa gestão da vida dos indivíduos é eminentemente médica, ela já surge medicalizada (não quer dizer com remédios, mas com uma ideologia médica). Chegando até o ponto atual em que é óbvio que o Estado médico se separou da pobreza, ele vai fazer parte da sociedade como um 
todo, de todas as classes. As classes mais favorecidas procurarão infinitamente mais a medicina individual, enquanto as classes menos favorecidas ficarão para os hospitais. Ficarão não mais para caridade, mas para uma parte da gestão pelo Estado que é coletiva. O hospital é um lugar coletivo, já foi um lugar de morte e caridade, mas agora é um lugar de saúde coletiva.

RAFAEL (CAFÉ COM NIETZSCHE) - Parece-me que caminhamos para tratar sobre as considerações de Foucault sobre a Biopolítica, certo?

VERA PORTOCARRERO (UERJ) - Perfeitamente. Afinal, do ponto de vista da gestão da vida dos indivíduos e das populações, um aspecto interessante que Foucault lembra e analisa é a biopolítica. Nessa gestão, você tem o fazer viver e o deixar morrer. Seria um contrassenso, para uma sociedade, a gestão do Estado ser uma gestão de majoração de vida, de melhora do estado de vida, que se morra nas mãos do Estado. Coisa que nós, aqui, conhecemos a partir da nossa periferia carente que é deixada morrer. Deixar morrer é o grande problema. Quando eu estava falando da história da caridade e dos hospitais, você tinha, antes, uma medicalização que era separada dos médicos dos indivíduos e que era um problema de caridade. Quem quiser que faça uma boa caridade. Já no momento pelo qual passamos, temos o fazer viver. Com o capital ainda no sentido do século XIX, a saúde passa a ser um dever do Estado e um direito. A saúde passa a ser um bem, mas um bem que também tem abre espaço para uma parcela que deve ser deixada para morrer. Deixa-se morrer um dissidente político ou uma população, que fazem parte da gestão do Estado, mas onde o Estado não penetra. Mesmo que aquela população tenha o direito afirmado pela constituição, nada se faz. Por exemplo, na atual pandemia, o Estado constrói os hospitais de campanha e, até o momento, não temos nada funcionando.

RAFAEL (CAFÉ COM NIETZSCHE) - Então, no tocante à medicina social como perspectiva Biopolítica, a senhora concordaria que, no Brasil, estamos na contramão do que se esperaria, hoje, no tempo da covid-19?

VERA PORTOCARRERO (UERJ) - Nós estamos na contramão de tudo! A contramão é tamanha que, em plena pandemia, nós já tivemos dois ministros da saúde, e estamos sem nenhum nesse momento ${ }^{2}$. O da educação foi para o espaço, e a educação está diretamente ligada à medicalização, e penetra na sociedade primeiramente a partir da escola e da família. Apenas não estamos na contramão disto que o Foucault falou na biopolítica, de que existe uma população que é deixada para morrer, a despeito da gestão da vida dos indivíduos e das populações. Aumentamos a estrada para o deixar morrer, sobretudo nas nossas comunidades.

VINÍCIUS CARVALHO (UFMS) - Apenas fazendo um adendo sobre essa problemática de se o Brasil está na contramão do mundo. Acho que depende da perspectiva. Nós estamos na contramão da ciência, das melhores práticas, da seriedade no campo político, o que significa também que estamos na vanguarda. $\mathrm{O}$ Brasil hoje é um dos líderes mundiais de um projeto irresponsável de morte, negacionismo e obscurantismo.

VERA PORTOCARRERO (UERJ) - O comentário do Vinícius foi de grande relevância, pois eu coloquei o Brasil na contramão de tudo e não levei em consideração a seriedade e a importância dos nossos cientistas. Mas, a atuação dos nossos cientistas vem sendo diminuída. Ora, qual é o ângulo que estou vendo ser traçado atualmente? Economia e pandemia. Com base nesta relação, vamos traçando as fases de relaxamento das medidas de isolamento. Então, esses cientistas, aos quais o Vinícius está se referindo, não têm muita voz. E por

2 O Ministro da Saúde, general Eduardo Pazuello, foi empossado ministro da saúde em 16 de setembro de 2020. O militar antes ocupava a secretaria executiva do Ministério e, após divergências do então ministro Nelson Teich com o Presidente Bolsonaro, permaneceu no cargo interinamente por quatro meses, conforme publicação de 03 de junho de 2020 no Diário Oficial da União. (Nota do revisor.). 
quê? Porque mesmo excelentes na área da saúde, da biologia e da estatística, eles precisam sair do governo, porque as instituições governamentais os expelem em nome de um avanço econômico. Claro que devemos tirar uma média entre a economia e a doença, pois quem pode ficar em casa são pouquíssimas pessoas. A maioria da população precisa sair para trabalhar porque não temos uma reserva para pôr na mão do trabalhador, na mão do pequeno empresário ou, se temos, então é muito difícil chegar na ponta mais necessitada.

VINÍCIUS CARVALHO (UFMS) - Um pequeno aparte. Por poucas pessoas no Brasil terem a possibilidade de ficar em casa, precisamos repensar o nosso modelo civilizatório, uma vez que as pessoas que não podem ficar em casa não o podem dentro do modelo civilizatório em que vivemos. Agora, se nós discutíssemos renda mínima universal, se nós discutíssemos o orçamento brasileiro, que geralmente ano a ano tem algo em torno de $40 \%$ destinado para pagar juros e amortizações de uma dívida que jamais foi auditada, como determinava a constituição de 1988, poderíamos encontrar alternativas ao modelo atual. Se nós não discutirmos isso, a massa comum dos brasileiros jamais terá uma base material mínima para poder ficar em casa durante uma pandemia. Então, é em virtude do modo como nós vivemos que o trabalhador não pode ficar em casa.

RAFAEL (CAFÉ COM NIETZSCHE) - Acerca dessa relação pandemia-economia, não parece que o Brasil se situa na contramão de outros países quando o governo federal trata a economia como opositora da saúde?

VINÍCIUS CARVALHO (UFMS) - O Brasil se tornou uma máquina de produzir falsas dicotomias. Somos um grande aparelho de distorção da realidade e de produção de falsas crises. Então, em um dado momento, reforçou-se uma escolha enganosa entre Saúde Pública e Economia. E quando se cria uma falsa dicotomia, gerando uma crise artificial, entra-se num loop do qual não se consegue sair. O mundo mais "avançado", que hoje é quase qualquer mundo fora do Brasil, percebeu que era um falso dilema escolher entre economia e saúde pública, porque o próprio campo da Saúde Pública é multidisciplinar e leva em conta indicadores econômicos. Esses indicadores impactam diretamente nos índices de saúde coletiva. O que fizemos no Brasil? Em vez de encarar a situação com seriedade, produzimos uma guerra de narrativas. Criamos um dilema entre proteger a economia e promover ações de Saúde Pública, e não fizemos nenhuma coisa nem outra. Se o Brasil está na contramão? Ele está na contramão das melhores práticas. O que o coloca na vanguarda de um certo obscurantismo bonachão, que se caracteriza por ser estapafúrdio. E como o Brasil não encarou com seriedade nem o problema de Saúde Pública e nem o problema econômico, está às voltas com uma crise cada vez mais complexa que cresce nos dois frontes. Como que o Brasil sairá disso? Não vejo hoje que o país reúna condições de possibilidade em seus núcleos de poder para enfrentar a crise, porque o Brasil se encontra imerso em uma crise política produzida, reproduzida e reforçada, dia após dia, por uma guerra de narrativas.

RAFAEL (CAFÉ COM NIETZSCHE) - Aproveitando que o professor Vinícius falou sobre negacionismo, cabe a pergunta: Até que ponto a dissociação pensada e reforçada historicamente entre ciência e sociedade leva às concepções negacionistas?

VINÍCIUS CARVALHO (UFMS) - Vou tentar estabelecer uma ponte entre o primeiro tópico, acerca da ontologia das entidades biopatológicas, e o problema do negacionismo. Queria partir do pressuposto de que as entidades biopatológicas são entidades fisicamente reais, dotadas de realidade objetiva. Não são meras construções ou narrativas, por mais que sua construção histórica tenha sido complexa. O conceito de uma entidade biopatológica, ou nosológica, como "Covid-19", diz respeito a algo cuja realidade é factual. Então, o que vemos é um confronto entre uma perspectiva realista e um relativismo extremo, pois o negacionismo é relativista. $\mathrm{O}$ obscurantismo que hoje vivemos quer forçar a realidade a adequar-se a determinadas narrativas ideológicas que satisfazem certos grupos de interesse. O debate entre realismo e relativismo não é novo. O autor Michael Redhead, em Da física à metafísica, fala do tribunal da medicina e da engenharia. 
É justamente o que nós estamos vivendo hoje. Este tribunal se apresenta como a instância que resolve, que liquida, essa querela entre o realismo e o relativismo. Nós até poderíamos ser relativistas com relação a teses mais ou menos esotéricas de cosmologia, de mecânica quântica, de física relativística - embora, justamente nessas áreas, realistas como Planck e Einstein sejam fortes e numerosos -, mas a medicina e a engenharia exigem de nós um compromisso inflexível com o real. Se você está em um quadro terminal ou foi diagnosticado com covid-19, ou se compromete com a realidade objetiva daquela entidade biopatológica e procura a assistência médica ou confia nos negacionistas de plantão. É muito fácil ser relativista até você entrar em um avião, pois quando entramos em um avião, confiamos que os engenheiros tenham sido bons realistas. O que nós vemos durante a pandemia é um palco onde o confronto entre o realismo e o relativismo ganha um novo capítulo. De um lado, temos a expertise da comunidade científica internacional. Do outro, temos narrativas inconsistentes e estapafúrdias, ricas em seu conteúdo de "pensamento ridículo". O que está em jogo é a saúde mesma da população. Estávamos falando a pouco de um mundo pós-pandemia, eu temo que com isso a própria pandemia se torne uma cortina de fumaça que nos impeça de perceber a gravidade da nossa situação, porque o mundo pós-pandemia é ainda um mundo distópico. Não será o mundo pós-distopia, uma vez que a pandemia é apenas uma das crises que vivemos. Entrando, portanto, no centro da questão do obscurantismo. O nosso momento está sendo marcado pela confluência de muitas crises: Temos uma crise de saúde pública global; temos uma crise da razão; uma crise da ciência; uma crise da universidade; uma crise das democracias; e como o Latour já alertou, temos pela frente o maior desafio de todos, que é a crise climática-ambiental, como um pano de fundo de todas as outras. E por mais que os negacionistas também tentem relativizar as mudanças climáticas, elas se tornaram matéria de consenso prático na comunidade científica internacional. Portanto, naquela escala de níveis de facticidade de Latour, o aquecimento global já é considerado um dado bruto do real, um fato. Nós vivemos uma crise ambiental que nos cobrará um preço altíssimo ao longo do século. Então, não nos enganemos com essa cortina de fumaça da pandemia. O mundo pós-pandêmico não é o mundo pós-distópico. Quando sairmos da pandemia ainda estaremos vivendo o epicentro da distopia, envoltos por um obscurantismo caracterizado por revisionismo histórico, negacionismo científico e autoritarismo político. Como subconjunto do autoritarismo político incluo a degradação dos valores humanísticos básicos que passam a ser relativizados diariamente. Todo esse obscurantismo não some com o fim da pandemia. Ele permanece no mundo pós-pandêmico e, dependendo do jogo de forças, talvez ainda saia mais forte do que entrou. Com relação a pergunta feita, de fato, historicamente a universidade, que tem uma tripla vocação de ensino, pesquisa e extensão, em muitos períodos se enclausurou como uma espécie de torre de marfim. Talvez dando muita ênfase à pesquisa e ao ensino e esquecendo de fazer essa ponte com a sociedade por meio da extensão. Ora, se ciência e sociedade andam em separado, se a sociedade não reconhece a ciência como parte de si e a ciência não se reconhece como prática social, há um divórcio que nos cobra um preço altíssimo. Nós criamos uma espécie de vácuo cultural, não preenchemos um espaço na sociedade. Se assim fazemos, deixamos esse espaço livre para o assalto dos obscurantistas, dos negacionistas, como os terraplanistas, isto é, para os que negam os fatos e são relativistas ao extremo. Sim, a universidade precisa fazer a sua autocrítica. Ela precisa construir pontes mais robustas com a sociedade. No entanto, o momento me parece tão grave que não julgo ser essa a ocasião mais propícia para autocrítica. Quando você está sendo atacado terrivelmente por todos os lados, cabe se defender. Precisamos defender a ciência, a universidade e a democracia.

\section{RAFAEL (CAFÉ COM NIETZSCHE) - Em sua leitura, há uma trama ou disputa para ocupar o lugar de onde se enuncia a verdade?}

VINÍCIUS CARVALHO (UFMS) - Acho que ao longo do século XX a verdade esteve em disputa e o lugar de onde ela pode ser enunciada também. E a noção de verdade veio sendo desconstruída. Em um certo sentido, ela veio sendo positivamente problematizada. Na Filosofia, na História, nas próprias ciências da natureza a pergunta “O que é a verdade?" se tornou uma questão premente e acredito que avançamos. Saímos de uma perspectiva um tanto quanto ingênua, problematizamos o conceito de verdade e nos tornamos um pouco mais sofisticados. Mas, em algum momento, nos perdemos. Em algum momento, confundimos pro- 
blematização com relativização. Em algum momento, confundimos a dimensão histórica e social das ciências com a possibilidade de que não existam verdades objetivas, mas apenas narrativas. Ora, se não existirem verdades objetivas, mas apenas narrativas, não temos porque procurar assistência medica, pois qualquer "solução" é válida. Então, me parece que a questão da verdade esteve em disputa e, como disse Bacon, Saber é Poder, o projeto da verdade é um projeto político, então, disputar a verdade é disputar o poder. Conseguir fazer prevalecer uma determinada visão ou teoria da verdade é colocar-se no epicentro de um tipo de poder. Quem está, hoje, no epicentro do poder? Não a verdade, mas a pós-verdade. Não os fatos, mas as fake news.

VERA PORTOCARRERO (UERJ) - Interessante a perspectiva do professor Vinícius. A esse respeito, eu estava pensando na questão do discurso verdadeiro, que é uma questão muito antiga. Certamente, conforme achamos em Bacon, saber é poder, mas vale a pena lembrar que poder também é saber. Um gera o outro. Eles têm uma relação de imanência e de geração mútua. E essas maneiras de funcionamento de verdade-poder, que estão sempre juntos e que não se confundem, remete a uma relação de forças. A verdade não está apenas na ciência, mas na ética, na política, na moral. Lembrando sempre que a verdade científica é provisória, ela é um processo. Hoje mesmo, em tempo recorde, nós temos a possibilidade de traçar o progresso da verdade científica, pois, com a pandemia, a ciência está trabalhando para achar soluções, enfrentando verdades e erros. Claro que se trabalha com modelos estatísticos que não conversam entre si, com modelos estatísticos diferentes que oferecem resultados mais ou menos interessantes para cada país, que os puxa para seu interesse político. Lembrando que aqui no Brasil mudamos o modelo estatístico dos óbitos com fins políticos ${ }^{3} . .$. Mas o importante é atentar para o fato de os países disporem de modelos que são cientificamente processuais e provisórios. E, como diria o velho Thomas Kuhn, eles brigam entre si. Veremos qual será o que irá se impor no tribunal da engenharia e da medicina, conforme o professor Vinícius destacou. Ressalto ainda que, diante de momentos de extrema turbulência nas ciências, a verdade e o erro não são claros. É justamente o que vemos neste período da covid-19, há uma linha muito tênue entre verdade e erro.

RAFAEL (CAFÉ COM NIETZSCHE) - Falou-se anteriormente que saber é poder, mas até que ponto estamos dentro de um estado de dominação que propaga um "não saber" como estratégia de poder? Foucault chegou a refletir sobre essa categoria?

VERA PORTOCARRERO (UERJ) - Não vejo Foucault pensar no não saber. Eu o vejo estudar as condições de possibilidade para o aparecimento de determinados saberes e também para certa percepção da loucura ou para certo olhar médico que contrastam ou constituem saberes científicos, por exemplo. Então, não vejo o Foucault falando em não saber. Na História da sexualidade I, por exemplo, ele toma os saberes desde os eruditos ou teóricos até os saberes daquelas pessoas que sabem. Não o da chamada doxa. Exemplo: O carcereiro, que sabe muito bem qual é o problema do crime, do presidiário etc. Este carcereiro sabe. Este é um tipo de saber. Assim, em Foucault, vejo um trabalho de busca das condições de possibilidade de existência dos saberes e, essa busca redundando na questão das condições políticas de possibilidade dos saberes. Não vejo ele falando de não saber. O negacionismo é outra coisa. Trata-se de uma situação contemporânea de desprezo da ciência em nome de práticas espúrias. Aqui, temos o negacionismo. Uma perspectiva ligada a uma forma de saber que poderia conduzir ao genocídio, por exemplo. Aliás, não sei se estamos longe disso. Então, penso que o negacionismo quer mais dizer o problema de você lidar com certas práticas e saberes que são preocupantes e não preferíveis na nossa sociedade. Curiosamente, estamos vivendo um paradoxo. Porque os saberes preferíveis estão no lugar dos saberes não preferíveis graças as formas de governo que estão se abatendo sobre nós.

3 Em 25 de maio de 2020, a Prefeitura do Município do Rio de Janeiro alterou a metodologia de contagem de óbitos por covid-19 tendo por indicador a causa mortis registrada na Certidão de Óbito. Indivíduos que não tivessem diagnóstico antes da emissão da certidão não seriam notificados. A metodologia gerou controvérsias e não apresenta evidências suficientes para orientar políticas públicas de combate à pandemia. Especialistas do Laboratório de Informações e Registros em Saúde da Escola Politécnica de Saúde Joaquim Venâncio da Fiocruz (EPSJV/Fiocruz) publicaram Nota Técnica contestando a metodologia. O documento pode ser acessado em $<$ https://portal.fiocruz.br/documento/nota-tecnica-registro-deobitos-por-covid-19-e-producao-de-informacoes-pelo-sus $>$. Último acesso em 29 de nov. 2020. (Nota do revisor.) 
RAFAEL (CAFÉ COM NIETZSCHE) - Professor Vinícius, como o senhor enxerga a valorização dos profissionais de saúde que estão na linha de frente no tratamento da covid-19?

VINÍCIUS CARVALHO (UFMS) - É indiscutível que os profissionais de saúde assumiram o protagonismo, fundamental nesse momento, e não são devidamente valorizados por aqueles que, agora, conduzem o país. Muito pelo contrário, se veem desrespeitados em suas manifestações. Como no caso da manifestação das enfermeiras, em Brasília, que foram objeto de violência verbal. Então, acredito que no mundo pós-pandemia, esses profissionais precisam ser devidamente valorizados e nossa sociedade deve render tributos de gratidão àqueles que estão na linha de frente nesse momento. No entanto, acredito que existem problemas que precisamos encarar para o futuro. Não só no que diz respeito a formação do profissional de saúde, como também no que diz respeito a certos valores e práticas que se fazem presentes nos sertões do Brasil afora e nas periferias das grandes cidades. Quer dizer, precisamos não só valorizar os profissionais de saúde, mas valorizar a saúde enquanto tal, e reforçarmos o pleito para uma saúde humanística em todo o Brasil. Vou contar um episódio que ocorreu quando era professor na Universidade Federal do Tocantins. Como parte do pós-doutoramento em Saúde Pública pelo Instituto de Medicina Social da UERJ, estive em aldeias indígenas. Vivi essa realidade. Então, posso lhe contar alguns episódios da situação de abandono que os nossos brasileiros indígenas enfrentam no que diz respeito ao acesso à saúde pública. Isso tem haver não só com a tomada de decisão de governadores e prefeitos, mas também com o dia-dia de contato entre profissionais de saúde e os indígenas. Há muitos relatos entre indígenas de falta de assistência, de maus tratos, de um atendimento frio e distante. É óbvio que temos que valorizar esses profissionais, que estão na linha de frente, fazendo um trabalho sem o qual nós não passaríamos. Eles têm fundamental importância, nós devemos ser gratos! Ao mesmo tempo, assim como devemos fazer autocrítica de todos os campos de atividade humana, acho que a sociedade brasileira, e a própria classe de profissionais da saúde, precisa pensar também sobre a formação humanística dos seus profissionais. Porque, infelizmente, muitos profissionais de saúde encamparam certos discursos moralmente problemáticos da ideologia de extrema-direita que, hoje, grassa no Brasil.

RAFAEL (CAFÉ COM NIETZSCHE) - Para finalizarmos, pergunto a professora Vera: Como a senhora acha que a educação poderia contribuir para driblar as estratégias políticas que selecionam quem deve viver e quem deve morrer neste tempo de pandemia?

VERA PORTOCARRERO (UERJ) - A educação vai ser colocada na nossa vida, e historicamente também, funcionando através de disciplinas. Disciplinas de conhecimento, mas por meio de um poder disciplinar que atua na anátomo-política do corpo que funciona na educação e na normalização que se estabelece por meio da educação. Isso acontece porque a anátomo-política do corpo tem mecanismos de educação como exames, estabelecimento de séries, anotações de dados, determinação de espaços e horários. Essa questão da educação vai funcionar como uma normalização ligada ao normal e ao patológico, mas sobretudo ao anormal. Por um lado, a normalização é o estabelecimento de uma homogeneização de todos. Por outro lado, essa homogeneização é uma estratégia que opera de tal modo que me permite distinguir cada um individualmente. Essa educação normalizadora, disciplinadora, é perigosa porque ela objetiva os sujeitos, transforma as subjetividades em objetos de normalização e, obviamente, de exclusão. A normalização funciona de tal modo que todo excluído resulta de uma vontade de inclusão. O normal, como diz Canguilhem, não existe. O normal é o anormal numa situação mais preferível. Primeiro, você localiza os anormais e depois sabe quem é o normal. Ora, se a educação for colocada como um sistema de dominação, de produção de indivíduos objetivados pelas estratégias políticas, normalizados, isso pode ser um perigo. É preciso que a educação tenha, obviamente, esse lado disciplinar... É preciso ter uma disciplina nesse momento de pandemia, seja lavar as mãos, seja limpar os sapatos, etc. Então, toda essa disciplina é importante, mas, por outro lado, a educação é a que possibilita a resistência. Nela está a própria resistência. Ela pode ser transformadora. Se pensar em Nietzsche, por exemplo, a educação é uma invenção, é uma possibilidade de criação. E essa possibilidade de criação é a possibilidade que eu tenho de, nesses limites espaço-temporais normalizados e disciplinados, localizar as zonas limítrofes 
de escape. Sem a criação ou invenção, nada anda. É só repetição, como diz Foucault, é só representação. É a filosofia da repetição. Para eu pensar numa educação que tenha uma função fundamental - e tem - é preciso tentar achar essas zonas de criação, de subjetivação e de construção de discursos de verdades processuais que consigam me trazer a possibilidade de fazer um diagnóstico do presente. Então, a educação só vai interessar para valer na medida em que permite fazer uma crítica e um diagnóstico do presente. Daí ser interessante a genealogia de Nietzsche, também a de Bruno Latour. Latour propõe, por exemplo, uma genealogia que nos permita chegar até o momento em que ciência e sociedade foram separados, em que razão e política foram separados. Temos que chegar até esse ponto e recompor o mundo, como diz Michel Serres, sem sermos hemiplégicos, isto é, sem ter só um lado. Então, a educação precisa ter esse escopo da possibilidade de diagnóstico do presente e da criação de novos possíveis. Se não, ela não interessa. 